\title{
DETERMINATION OF TRACE QUANTITIES OF THORIUM IN URANYL NITRATE BY X-RAY EMISSION SPECTROMETRY
}

\author{
William I. Winters
}

Chemical Technology Laboratory

Research and Development Chemical Processing Division

October 1973

\section{ATLANTIC RICHFIELD HANFORD COMPANY RICHLAND, WASHINGTON 99352}

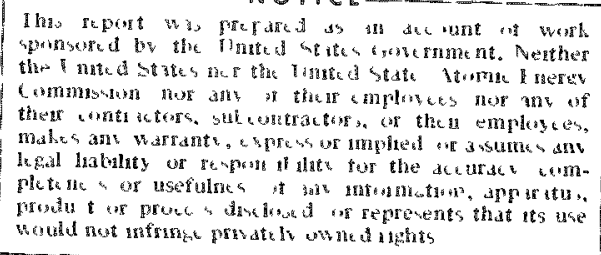

AEC RL RICHLATAD WASH

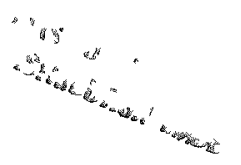




\section{DISCLAIMER}

This report was prepared as an account of work sponsored by an agency of the United States Government. Neither the United States Government nor any agency Thereof, nor any of their employees, makes any warranty, express or implied, or assumes any legal liability or responsibility for the accuracy, completeness, or usefulness of any information, apparatus, product, or process disclosed, or represents that its use would not infringe privately owned rights. Reference herein to any specific commercial product, process, or service by trade name, trademark, manufacturer, or otherwise does not necessarily constitute or imply its endorsement, recommendation, or favoring by the United States Government or any agency thereof. The views and opinions of authors expressed herein do not necessarily state or reflect those of the United States Government or any agency thereof. 


\section{DISCLAIMER}

Portions of this document may be illegible in electronic image products. Images are produced from the best available original document. 
TABLE OF CONTENTS

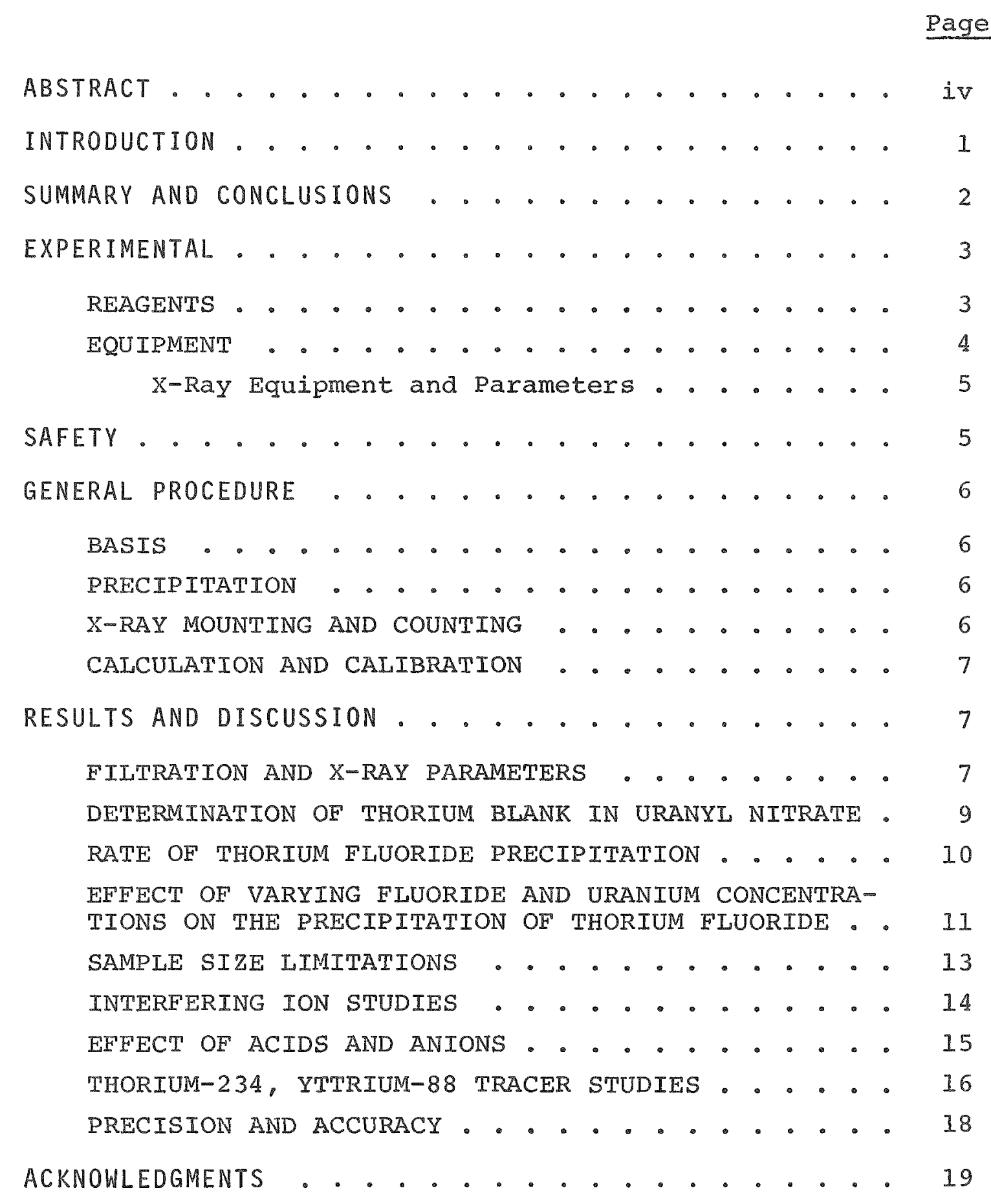


TABLE OF CONTENTS (continued)

Page

REFERENCES . . . . . . . . . . . . . . . 20

FIGURES • • • • . . . . . . . . . . . . . 21

APPENDIX: DETAILED PROCEDURE FOR THE DETERMINATION

OF THORIUM IN URANIUM NITRATE ...... 25 


\section{ABSTRACT}

Irace quantities of thorium in uranium were separated by precipitating thorium fluoride from a 1.OM HF-1.OM NH ${ }^{\prime}$ matrix using yttrium as an internal standard and lanthanum as a carrier. The thorium precipitate was collected on a fizter and analyzed by X-ray emission spectrometry. The method has a detection limit of about $15 \mathrm{Hg}$ thorium per gram of uranium. The relative accuracy and precision at the 120 $\mu g$ thorium zevel was $95.5 \pm 1.5 \%$. Studies on the rate of precipitation, sample size limitations, and the effect of varying molar fluoride-to-uranium ratios are discussed. The effeets of potentialzy interfering anions, cations, and acids which are commonly found in uranium system or form insoluble fluorides were studied. Radioactive tracer studies using ${ }^{234}$ Th and ${ }^{88} Y$ were carried out at different levels of thorium and uranium to determine the absolute efficiency of the precipitation. The speed, selectivity, and precision of this $X-r a y$ method make it an excezlent alternative to spectrophotometric methods. 


\section{DETERMINATION OF TRACE QUANTITIES OF THORIUM \\ IN URANYL NITRATE BY X-RAY EMISSION SPECTROMETRY}

\section{INTRODUCTION}

INumerous methods $[1,2]$ have been described for the separation and determination of trace quantities of thorium in uranium. Most of these are based on a spectrophotometric determination of thorium and require a very efficient separation of thorium from uranium and other impurities since the spectrophotometric reagents are not very selective. Solvent extraction and ion exchange techniques have been used extensively for separating thorium from uranium; however these methods may be long and complicated and are not always suitable for routine analyses. Precipitation of thorium fluoride has been used as the basis of spectrometric [3] and volumetric [4] determinations of thorium in uranium. However in both these methods the precipitate must be isolated and redissolved before analyzing.

Luke [5,6] has described a technique for separating trace elements by coprecipitation, filtration onto Millapore $(\mathbb{R})$ (txade name of Millipore Corporation) filters, and subsequent determination of the elements by $\mathrm{X}$-ray emission analysis. Since precipitation of thorium fluoride $\left(\mathrm{ThF}_{4}\right)$ and $X-r a y$ analysis appeared to offer a rapid method of separating, concentrating, and analyzing trace quantities of thorium in uranium, it was decided to investigate the application of these techniques in the analysis of thorium in uranyl nitrate. 


\section{SUMMARY AND CONCLUSIONS}

A method for the determination of trace quantities of thorium in uranium was developed. Thorium was separated from uranyl nitrate by precipitating thorium fluoride from

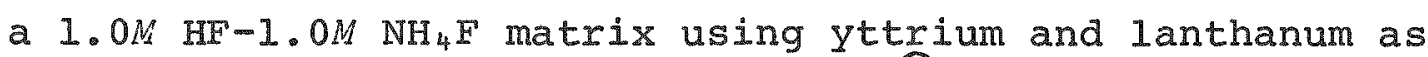
carriers and collecting on solvinert ${ }^{(B)}$ (trade name, Millipore Corporation) Millipore filters. The thorium on the filter was then analyzed by $\mathrm{X}$-ray emission spectrometry using the yttrium on the filter as an internal standard. The method has an accuracy of $67.5 \pm 6.0 \%$ at a thorium level of 16 parts per million parts uranium ( $\mathrm{pTh} / \mathrm{mpU}$ ) and $95.5 \pm 1.5 \%$ at the $120 \mathrm{pTh} / \mathrm{mpU}$ level.

The thorium fluoride precipitation rate was studied with and without the presence of uranium and was found to be complete after 15 minutes. Results from tests in which the quantities of uranium and fluoride were varied indicate that quantitative precipitation of the thorium occurs when the molar ratio of fluoride-to-uranium is between 10 to 1 and 15 to 1. If this ratio is maintained, quantitative recoveries can be obtained for sample sizes as large as $4.0 \mathrm{ml}$ of 500 g/liter uranyl nitrate. If the ratio drops below 10 to 1 , high percent recoveries occur due to selective incomplete precipitation of yttrium. The effect of seven cations and four anions and acids were studied. Since most cations form soluble fluoride complexes only potentially insoluble fluorides were studied. When calcium and strontium were spiked into a uranium standard at $500 \mu \mathrm{g}$ levels, additional precipitate was visible on the filter and occasional low results (90\% recoveries) were obtained. Lead also precipitated but caused the percent recoveries to be greater than $110 \%$ when over $500 \mu \mathrm{gb}$ were added to a uranium standard. The high recoveries were caused by an $x$-ray spectral overlap 
of the Pb LB X-ray with the Th La, X-ray peak. No significant errors $(> \pm 10 \%)$ were produced when two milliequivalents of $\mathrm{HCl}$ or $\mathrm{H}_{2} \mathrm{SO}_{4}$ were added to the procedure. Trace amounts of phosphate cause no significant errors. However, when greater than eight milliequivalents of $\mathrm{HNO}_{3}$ were added to the procedure, recoveries greater than $110 \%$ were obtained. In order to determine the actual percent of thorium and yttrium precipitated, the method was carried out using radioactive tracers ${ }^{234} \mathrm{Th},{ }^{88} \mathrm{Y}$ at different concentrations of thorium and uranium. These tests showed that approximately $90 \%$ of the yttrium and thorium was precipitating under the conditions of the procedure. The low percent recoveries for the thorium at the $16 \mathrm{pTh} / \mathrm{mpU}$ level are probably because the solubility for thorium fluoride is becoming significant. However the excellent precision of the method at this concentration should make it possible to measure this level of thorium if properly calibrated. Since the method provides a rapid, selective, and precise analysis of thorium in large amounts of uranium, it has many advantages over longer, less selective spectrophotometric methods and should find increased usage in uranium specification analysis.

\section{EXPERIMENTAL}

\section{REAGENTS}

Lanthanum Carrier Solution ( $1.00 \pm 0.1 \mathrm{~g} / 1$ iter La): Dissolve 1.172 grams of $\mathrm{La}_{2} \mathrm{O}_{3}$ in $100 \mathrm{ml}$ of concentrated $\mathrm{HCl}$ and bring to volume with deionized $\mathrm{H}_{2} \mathrm{O}$ in a l-liter volumetric flask.

Yttrium Internal Standard Solution $1.000 \pm 0.001$ g/Iiter $\mathrm{Y})$ : Dissolve 1.2698 grams of $\mathrm{Y}_{2} \mathrm{O}_{3}$ in $100 \mathrm{ml}$ of concentrated $\mathrm{HCl}$ and bring to volume with deionized $\mathrm{H}_{2} \mathrm{O}$ in a l-liter 
volumetric flask.

Fluoride Solution (1.OM HF-1.0M $\left.\mathrm{NH}_{4} \mathrm{~F}\right)$ : Dissolve 37.04 grams of $\mathrm{NH}_{4} \mathrm{~F}$ and $35 \mathrm{ml}$ of $48 \% \mathrm{HF}$ in deionized $\mathrm{H}_{2} \mathrm{O}$ and bring to volume in a 1-liter volumetric flask. Store the fluoride solution in a polyethylene bottle. Wear gloves when handling HF and resulting solutions.

Thorium Standard (1.0000 g/liter Th): The thorium standard used in these studies was prepared by diluting a standard thorium nitrate solution that had been standardized by the gravimetric determination of thorium dioxide.

Uranyl Nitrate Standard (481.41 g/liter uranium): This was made from $\mathrm{UO}_{3}$ powder and standardized gravimetrically by converting and weighing as $\mathrm{U}_{3} \mathrm{O}_{8}$. This solution was $0.22 \mathrm{M}$ in $\mathrm{HNO}_{3}$.

\section{EQUIPMENT}

Polyethylene beakers--30 and $50 \mathrm{ml}$.

Milipore Filtering Apparatus--25-mm filter size.

Milipore Solvinert Filters--25-mm diameter, 0.25-micron pore size.

Rubber policeman.

Teflon stir bars.

Mylar- $-\left(0.00025^{\prime \prime}\right) 1 / 4 \mathrm{mil}$.

Capplug--SEP-14 cut to a 6-mm height with no bottom (Figure 1).

Capplug Division

Protective Closures Company

2151 Elmwood Avenue

Buffalo, NY 14207

Plastic Cafe Curtain Rings--inside of curtain ring is trimmed so that ring will fit over Capplug and filter paper. 
Meine Mathanson, Inc. 160 Fifth Avenue New York, NY

X-Ray Equipment and Parameters

X-Ray Spectrometer-General Electric XRD-5 with 700 series detection system.

Molybdenum X-Ray Tube--operated at 50 kilovolts (kV) and 40 milliamps (mA).

Diffraction Crystal--LiF, $2 d=4.0267$.

Pulse Height Selector--set to discriminate against second order cadmium $\mathrm{K} \beta \mathrm{X}$-rays.

Collimation--0.005" Soller silts.

Count Time--100 seconds for all peaks.

Air Path

Sample Mask--circular aluminum mask the same diameter as the SEP-14 Capplug.

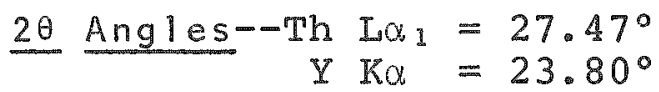

\section{SAFETY}

Solutions and wastes containing hydrofluoric acid (HF) can cause severe burns when they come in contact with the skin. Therefore rubber gloves should be worn whenever these solutions are handled and all spills cleaned up immediately using large amounts of water. If the skin should come in contact with HF, the area contacted should be immediately washed with copious amounts of water and then treated by a qualified physician. 


\section{GENERAL PROCEDURE}

\section{BASIS}

Lanthanum fluoride precipitate is used as a carrier in the precipitation of $\mathrm{Th}$ and $\mathrm{Y}$ fluorides. After filtration, the filter is analyzed by $X-r a y$ emission to determine the

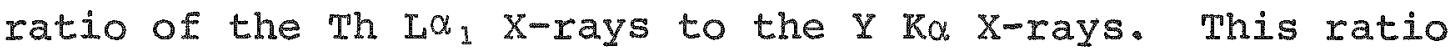
is proportional to the Th concentration as determined by a prior calibration.

\section{PRECIPITATION}

Pipet two mililiters of uranyl nitrate ( $\approx 500 \mathrm{~g} / \mathrm{liter})$ into a plastic beaker containing $30 \mathrm{ml}$ of $1.0 \mathrm{MF}-1.0 \mathrm{M} \mathrm{NH}_{4} \mathrm{~F}$ solution. Add $200 \mu 1(200 \mu \mathrm{g})$ of the $1.0 \mathrm{~g} / 1 \mathrm{iter}$ lanthanum carrier solution to the beaker. Pipet exactly $200 \mu I$ (200 $\mu \mathrm{g})$ of the $1.0 \mathrm{~g} / 1$ iter yttrium internal standard solution into the beaker and stir for 10 minutes using a Tefloncoated stir bar. After stirring, allow the solution to stand 30 minutes and then filter the solution through a Milipore filtering apparatus containing a 25-mm solvinert filter. Rinse the beaker with two $2.5-\mathrm{ml}$ portions of $1.0 \mathrm{M}$ $\mathrm{HF}-1.0 \mathrm{NH} \mathrm{NH}_{4}$ and filter. Finally rinse down the sides of the filtering apparatus with approximately $5 \mathrm{ml}$ of ethanol. After all the rinse solution has been pulled through the filter by the vacuum, carefully remove the chimney and the filter. Allow the filter to dry in the air before preparing the $x$-ray mount.

\section{X-RAY MOUNTING AND COUNTING}

Place a $2^{\prime \prime}$ square piece of Mylar on an SEP-14 Capplug. Place the dried filter paper on the Mylar with the precipitate side up and center over the capplug. Cover the filter 
paper with a second piece of Mylar. Snap a trimmed curtain ring over the capplug keeping the filter centered. This unit is then wrapped in another piece of Mylar which is $6^{\prime \prime}$ square. The mounting technique is shown in Figure 1. The mount is then placed in the $x$-ray and analyzed with the parameters previously described.

\section{CALCULATION AND CALIBRATION}

A mount containing a clean solvinert filter is counted at the $Y \operatorname{Ko}\left(23.80^{\circ} 2 \theta\right)$ and $L a \operatorname{L\alpha } \alpha_{1}\left(27.47^{\circ} 2 \theta\right)$ peaks before and after counting the samples and standards. The counts on this blank mount are then averaged for each peak and subtracted from the gross count of the samples or standards at the respective peak. After the samples have been corrected for the background, the net count/second (C/S) value for the Th is ratioed to the net $\mathrm{C} / \mathrm{S}$ value for yttrium. This value is then used to determine the concentration of $T h$ from a least squares calibration.

The method is calibrated by carrying known aliquots of the Th standard $(12.5 \mu \mathrm{g}$ to $250 \mathrm{\mu g})$ through the procedure without any uranium. The linear relationship of the ratio C/S Th per C/S $Y$ to concentration of $T h(\mu g)$ may be described by a linear equation obtained from a least squares evaluation of the calibration data. An example of the calibration data and curve are shown in Table I and Figure 2.

\section{RESULTS AND DISCUSSION}

\section{FILTRATION AND $X-$ RAY PARAMETERS}

The use of hydrofluoric acid (HF) in the precipitation requires that the apparatus and filter be essentially chemically inert. Millapore Solvinert filters were chosen since 


\section{TABLE I}

TYPICAL CALIBRATION DATA

\begin{tabular}{rrrr} 
g Net C/S Th & Net C/S Y & RatioC/S Th:C/S Y \\
\cline { 1 - 1 } 12.48 & 40.67 & 1581.73 & 0.02571 \\
24.96 & 69.22 & 1797.20 & 0.03852 \\
49.92 & 103.20 & 1400.62 & 0.07368 \\
99.84 & 298.33 & 1795.03 & 0.16620 \\
149.76 & 394.23 & 1662.21 & 0.23717 \\
199.68 & 584.46 & 1754.33 & 0.29901 \\
249.60 & 613.81 & 1632.45 & 0.37601 \\
Average background: & $T h=94.06 \mathrm{C} / \mathrm{S}$ \\
& $Y=114.53 \mathrm{C} / \mathrm{S}$.
\end{tabular}

they do not react with concentrated acids or alkalies. Solvinert filters offer another advantage over other inert filters in that their tan color makes it possible to see a white precipitate, which permits accurate centering of the filter on the Capplug. Plastic beakers and Teflon stir bars are used to prevent any loss of precipitate on etched glass and the nonwetting characteristics of plastic make quantitative transfers much easier. The only glass used in the procedure is in the filter apparatus. Water and precipitate will tend to cling to the glass; however the final alcohol wash appears to remove any residual water or precipitate. After repeated use the glass frit in the filter apparatus will eventually deteriorate and fall out. This effect will first be evident when a precipitate forms in the filtration flask. Replacing the glass frit with a plastic support should extend the life of the filtration apparatus.

The Capplugs' height have been reduced so that they fit easily into the sample holder for the XRD-5 instrument, and the bottoms removed in order to reduce the background from scattered $x$-rays. The molybdenum $x$-ray tube gives the optimum peak-to-background ratios for the Th analyses. 
Platinum $X-r a y$ tubes have been used but the Pt Lr X-rays from the tube increase the Th background count. Second order $C d \mathrm{~K} B \mathrm{X}$-rays which appear to originate in the sample holder are removed by pulse height selection, resulting in improved peak-to-background ratios for $\mathrm{Th}$. The $0.005^{\text {" }}$ Soller slits were originally chosen to insure adequate separation of the Th $\left(27.47^{\circ} 2 \theta\right)$ and $U\left(26.14^{\circ} 2 \theta\right)$ peaks. If separations are obtained which contain less than $100 \mathrm{\mu g} \mathrm{U}$, it may be possible to use $0.01^{\prime \prime}$ Soller slits and improve the count rate at lower concentrations of Th. In addition to using a blank mount for background correction, a background count was made on each mount at $25.00^{\circ} 2 \theta$. However no advantages appeared to be gained using the background count and since a blank mount required less counting time. it was decided to use the blank mount background correction.

DETERMINATION OF THORIUM BLANK IN URANYL NITRATE

One of the major problems in testing this procedure for trace Th in uranium was finding a uranium standard that contained an accurately known amount of thorium. The uranium standard used in all the tests in this document contained $481.41 \mathrm{~g} / \mathrm{liter} \mathrm{U}$ and $0.22 \mathrm{M} \mathrm{HNO}_{3}$. Three aliquots of this standard were analyzed by the method described earlier with the exception that only $20 \mathrm{ml}$ of $1.0 \mathrm{MHF}-1.0 \mathrm{M} \mathrm{NH} \mathrm{N}_{4}$ were used. The results are shown in Table II. Several observations were made during this experiment. Compared with the calibration data, the yttrium count rate was lower for the 3- and 4-ml uranium aliquots. These low yttrium counts indicate incomplete precipitation of the $\mathrm{Y}$ resulting in high Th-to-Y ratios and the steady increase in the Th $\mu \mathrm{g} / \mathrm{ml}$ value. The reasons for the low yttrium results are discussed later in the uranium-to-fluoride ratio studies. The $6.13 \frac{\mu \mathrm{g}}{\mathrm{ml}} \mathrm{Th}$ result for the $2-\mathrm{ml}$ aliquot was near the 
TABLE II

DETERMINATION OF RESIDUAL THORIUM IN URANIUM STANDARD

$\begin{array}{ccc}\frac{\text { U Standard }}{\mathrm{mI}} & \frac{\mathrm{Th} \text { Found }}{\mu \mathrm{g} / \mathrm{mI}} & \frac{\text { Ratio }}{M \text { F/MU }} \\ 2 & 6.13 & 9.9 \\ 3 & 7.57 & 6.6 \\ 4 & 10.29 & 4.9\end{array}$

measurement limit, and therefore not highly accurate. In order to obtain a more accurate value for the residual $\mathrm{Th}$ in the $U$ standard, the method of standard additions was applied to a series of $1-\mathrm{ml}$ aliquots of the uranium standard. Thorium spikes of $12.5,25.0,50.0$, and $100.0 \mathrm{\mu g}$ were added to separate 1-ml aliquots of the uranium standard. In addition, a l-ml aliquot without a spike was also analyzed and this point included in the analysis of the data. The result of the test was a linear curve that had an intercept on the concentration axis of $7.77 \mathrm{\mu g} / \mathrm{ml}$ Th as determined from the least squares equation for the line. This value, $7.77 \mathrm{\mu g}$ $\mathrm{Th} / \mathrm{mI} \mathrm{U}$, was used to correct results of other tests for the Th that was already present in the uranium standard.

\section{RATE OF THORIUM FLUORIDE PRECIPITATION}

In order to establish that the precipitation was complete and not a function of time, two tests were carried out in which the digestion time was varied from 5 to 45 minutes. one test was run with a 100- $\mu$ g Th aliquot and no uranium and another with $100-\mu \mathrm{g} T \mathrm{Th}$ and $3 \mathrm{ml}$ of the $481.41 \mathrm{~g} / \mathrm{liter}$ uranium standard. The results of these tests are shown in Table III.

In Test 1 there appeared to be a slight increase in the count rate for both $\mathrm{Th}$ and $\mathrm{Y}$ as the digestion time was increased; however the results indicate that no significant 


\section{TABLE III}

\section{RATE OF $\mathrm{ThF}_{4}$ PRECIPITATION}

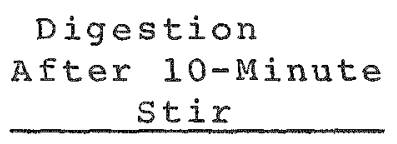

5

10

20

30

45

\begin{tabular}{r} 
Test 1 \\
Th no U \\
\hline Recover \\
\hline 105.4 \\
101.5 \\
99.2 \\
99.1 \\
109.8
\end{tabular}

$$
\begin{gathered}
\text { Test } 2 \\
\text { Th-3 mI U } \\
\hline \text { Recovery } \\
\hline
\end{gathered}
$$

110.5

123.6

116.4

108.4

109.4

changes in the ratio of $\mathrm{Th} / \mathrm{Y}$ and the percent recovery for Th occurred. No significant changes in Th and $Y$ count rate were apparent in Test 2 with uranium. The high percent recoveries can be explained by the ratio of the fluoride to the uranium as noted in the following sections. These data indicate that the method is complete within 5 minutes after stirring; however all other tests in this document used a 30-minute digestion time since these data may not necessarily be extrapolated to other concentrations of Th.

EFFECT OF VARYING FLUORIDE AND URANIUM CONCENTRATIONS ON THE PRECIPITATION OF THORIUM FLUORIDE

In order to determine the maximum uranium sample size, an experiment was conducted in which the Th spike was held constant at $100 \mathrm{\mu g}$, the amount of $1.0 \mathrm{M} \mathrm{HF}-1.0 \mathrm{M} \mathrm{NH} 4 \mathrm{~F}$ was held constant at $20 \mathrm{ml}$, and the amount of $481.41 \mathrm{~g} / 1$ iter uranium varied from $250 \mu \mathrm{l}$ to $4 \mathrm{ml}$. The results of these tests are shown in Table IV.

When over $2 \mathrm{ml}$ of $481.41 \mathrm{~g} / \mathrm{liter}$ uranium were added, the precipitation of $\mathrm{Y}$ became incomplete causing high percent recoveries for the thorium. Figure 3 illustrates the effect of the fluoride-to-uranium ratio on the thorium recovery and indicates that the molar $\mathrm{F}^{-} / \mathrm{U}$ ratio should be greater than 
10 for quantitative results.

TABLE IV

EFFECT OF VARYING URANIUM CONCENTRATION

ON THE DETERMINATION OF THORIUM

\begin{tabular}{|c|c|c|}
\hline $\mathrm{mI} \quad \mathrm{U}$ & Ratio & Th \\
\hline Added & $M F / M \quad U$ & Recovery \\
\hline 0.25 & 79.27 & 93.4 \\
\hline 0.50 & 39.55 & 96.7 \\
\hline 1.00 & 19.77 & 93.2 \\
\hline 2.00 & 9.89 & 96.9 \\
\hline 3.00 & 6.67 & 129.3 \\
\hline 4.00 & 1.66 & 269.0 \\
\hline
\end{tabular}

A similar test was performed to determine the effect of varying the amount of $1.0 \mathrm{MHF}-1.0 \mathrm{M} \mathrm{NH}_{4} \mathrm{~F}$ with a constant amount $(2 \mathrm{ml})$ of $481.41 \mathrm{~g} / \mathrm{liter} U$ on the determination of $100 \mathrm{\mu g} \mathrm{Th}$. The data for this experiment are shown in Table V.

\section{TABLE $V$}

EFFECT OF VARYING THE AMOUNT OF $1.0 \mathrm{M} \mathrm{HF-1.OM} \mathrm{NH}_{4} \mathrm{~F}$ ON THE DETERMINATION OF THORIUM

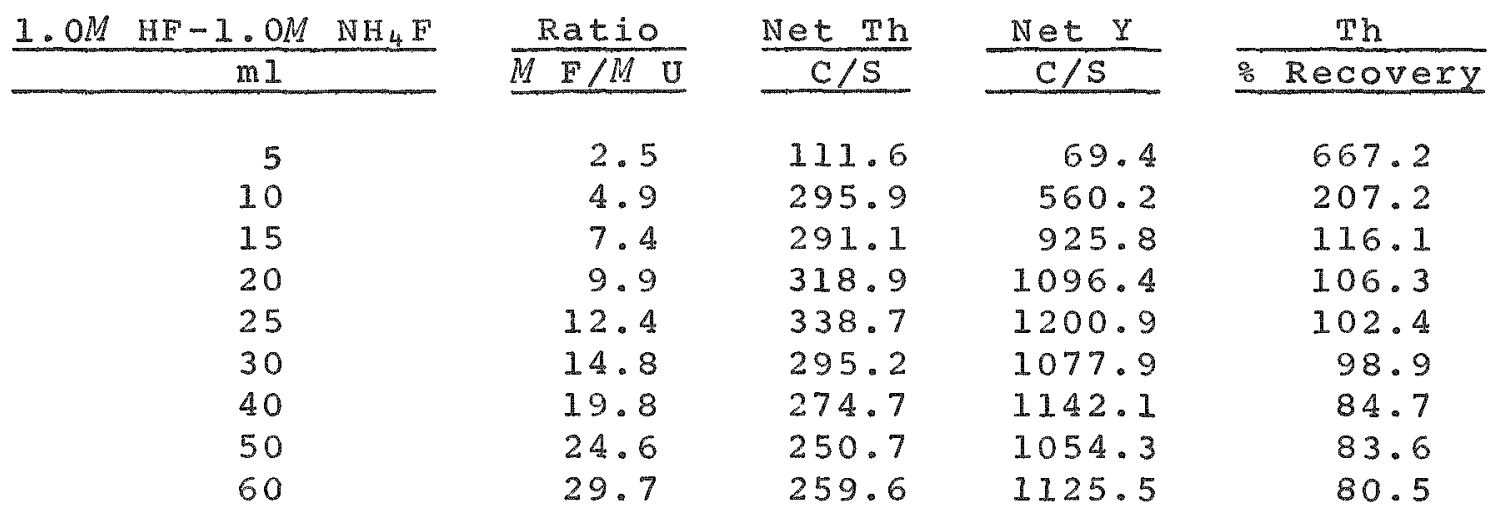

Again the high percent recoveries on small $F^{-} / 0$ ratios resulted from incomplete precipitation of the yttrium. For comparison from the first test with varying uranium, a plot of the ratio of $F^{-/ U}$ versus $T h$ percent recovery is shown 
in Figure 4. Data indicate that there is a decrease in the thorium count rate and percent recovery when the molar ratio of fluoride-to-uranium is greater than about 15. The loss of thorium may be due to the formation of anionic thorium fluoride complexes: however data from the first test with varying uranium indicated that good recoveries (>90\%) were possible at $F^{-} / U$ ratios as high as $c a .80$. Therefore this thorium loss may be attributed to physical losses in handling larger volume samples. From these two studies it may be concluded that in order to insure quantitative results the ratio of fluoride-to-uranium should be greater than 10 to 1 and preferably between 10 and 15 to 1 . Also the total volume should be controlled so that it is approximately 30 m1 or less.

\section{SAMPLE SIZE LIMITATIONS}

Earlier attempts to analyze thorium in sample sizes greater than $2 \mathrm{ml}$ of $500 \mathrm{~g} / \mathrm{liter}$ uranium using only $30 \mathrm{ml}$ of the fluoride reagent resulted in low yttrium count rates and higher thorium values with increasing sample size. Data from the fluoride and uranium ratio studies indicated that by increasing the amount of fluoride reagent it would be possible to obtain consistent recoveries with larger sample sizes. Duplicate tests of 3 and $4-\mathrm{ml}$ sample sizes were analyzed with 100-ing thorium spikes and 40 and $50 \mathrm{ml}$ of fluoride reagent, respectively. Only the volume of 1.0M HF1. $O M \mathrm{NH}_{4} \mathrm{~F}$ reagent was changed in the procedure. Table VI shows the outcome of these tests.

Analysis of larger amounts of uranium should be possible as long as the fluoride-to-uranium ratio is in the correct range, the volume does not become so large that losses due to handling occur, or the thorium concentration is so low 
that the solubility product of thorium fluoride is not exceeded.

\section{TABLE VI}

EFFECT OF INCREASING THE AMOUNT OF FLUORIDE ON THE DETERMINATION OF THORIUM IN LARGER AMOUNTS OF URANIUM

\begin{tabular}{|c|c|c|c|c|}
\hline 0 & $1 \mathrm{H} \mathrm{HF}-1 \mathrm{MNNH}_{4} \mathrm{~F}$ & Ratio & & $\mathrm{Th}$ \\
\hline Volume, ml & Volume, $\mathrm{ml}$ & $M E / M U$ & $\mathrm{pTh} / \mathrm{mpU}$ & Recovery \\
\hline 3 & 40 & 13.2 & 85 & 93.8 \\
\hline 3 & 40 & 13.2 & 85 & 98.2 \\
\hline 4 & 50 & 12.4 & 69 & 94.2 \\
\hline 4 & 50 & 12.4 & 69 & 97.4 \\
\hline
\end{tabular}

INTERFERING ION STUDIES

Under normal conditions less than $50 \mu \mathrm{g}$ of uranium remained on the mount after filtering and washing. This quantity of uranium does not spectrally interfere with the determination of Th to any measurable extent. In addition to uranium, the effects of several other elements were tested by spiking $2 \mathrm{ml}$ of the $481.41 \mathrm{~g} / \mathrm{liter}$ uranium standard with varying quantities of the ion of interest and with $100 \mathrm{\mu g}$ of Th. Ions studied were either elements commonly found as impurities in the uranium ( $\mathrm{Al}, \mathrm{Fe}, \mathrm{Ca}$ ) or elements that may possibly form insoluble fluoride. The results of these tests are shown in Table VII.

Calcium, silver, and strontium definitely precipitated as noted from the amount of precipitate on the filter. Some of the results indicated that $\mathrm{Sr}$ and $\mathrm{Ca}$ may cause low percent recoveries. However these data were inconsistent and therefore the results may depend on the manner in which the precipitate was distributed on the filter. Increasing amounts of $\mathrm{Pb}$ caused increasing recoveries due to the $\mathrm{Pb} L / \beta$ spectrum which is near the $T h L \alpha_{1}$ peak. The effect of $A I$ and Fe at the $500 \mathrm{\mu g}$ level was insignificant; however if these 


\section{TABLE VII}

EFFECT OF INTERFERING IONS ON THE DETERMINATION OF THORIUM

$\begin{array}{crr}\begin{array}{c}\text { Interfering } \\ \text { Element }\end{array} & \frac{\text { Concentration }}{\mu g} & \begin{array}{r}\text { Recovery } \\ \text { of Th }\end{array} \\ \text { Ag } & 250 & 96.2 \\ & 500 & 100.0 \\ \text { Sr } & 100 & 103.2 \\ & 250 & 91.8 \\ \text { Pb } & 500 & 98.6 \\ & 100 & 103.9 \\ \text { A1 } & 250 & 108.7 \\ \text { Fe } & 500 & 113.2 \\ \text { Ca } & 500 & 93.4 \\ & 500 & 96.3 \\ \text { Ba } & 100 & 102.0 \\ & 250 & 104.2 \\ & 500 & 85.6 \\ & 100 & 99.9 \\ & 500 & 96.1\end{array}$

ions, or other ions which form complex fluorides, were present in quantities high enough to reduce the effective fluoride-to-uranium ratio they may cause high results due to incomplete precipitation of the yttrium internal standard as discussed earlier. The effect of digestion time on the precipitation of interfering ions was not studied but better separation of the thorium from the $\mathrm{Pb}, \mathrm{Ca}$, and $\mathrm{Sr}$ could possibly result if it were optimized. The method appears to be reasonably free of interferences due to impurity ions; however if it is applied to uranium samples containing large amounts of the alkali earth or lead, it may be necessary to modify the proposed procedure.

EFFECT OF ACIDS AND ANIONS

In order to study the effect of different acids and 
anions on the determination of thorium in uranium, $2 \mathrm{ml}$ of the $481.41 \mathrm{~g} / \mathrm{liter}$ uranium standard containing $0.220 \mathrm{M} \mathrm{HNO}_{3}$ was spiked with $100 \mathrm{\mu g}$ of thorium and various quantities of the acid or anion of interest. The following table lists the amounts of acids and anions used in the tests performed and the thorium percent recoveries.

\section{TABLE VIII}

EFFECT OF ACIDS AND ANIONS ON THE DETERMINATION OF THORIUM IN URANIUM

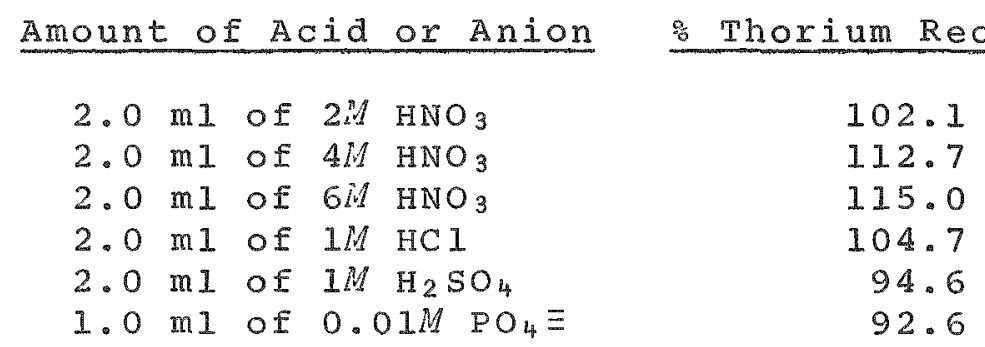

Greater than 8 milliequivalents of $\mathrm{HNO}_{3}$ causes high recoveries as a result of incomplete precipitation of yttrium. chloride, sulfate, and phosphate did not significantly interfere at the levels studied.

\section{THORIUM-234, YTPRIUM-88 TRACER STUDIES}

Even though excellent results were being obtained with the method, no indication of the actual efficiency of the precipitation was possible since the results were based on the ratio of thorium-to-yttrium. Radioactive tracers were used to determine the percent of thorium and yttrium precipitated. The ${ }^{234} \mathrm{Th}$ content of the $481.41 \mathrm{~g} / 1$ iter uranium standard was determined by analyzing a 1-ml aliquot by gamma energy analysis of $234 \mathrm{mPa}$, the daughter of ${ }^{234} \mathrm{Th}$. The ${ }^{234}$ Th in the uranium standard was then used as the thorium tracer. A $100-\mu 1$ spike of $0.556 \mu \mathrm{Ci} / \mathrm{ml}{ }^{88} \mathrm{Y}$ was used as the yttrium tracer. Three tests were carried out in 
which the volume of uranium standard was held constant at $2.0 \mathrm{ml}$ and the nonradioactive Th spike varied. In another series of tests the nonradioactive Th spike was held constant at $100 \mu \mathrm{g} \mathrm{Th}$ and the amount of uranium standard used was varied. The samples were analyzed as described previously except the filters were mounted face-down in stainless steel gamma mounting dishes rather than $\mathrm{X}$-ray Capplug mounts. The mounts were allowed to stand 10 minutes before counting in order to allow the $234 \mathrm{Th}$ to come into equilibrium with its daughter $234 \mathrm{mPa}$ whose $1.000 \mathrm{MieV}$ gamma was used to determine the Th yield. The precision of the ${ }^{88} \mathrm{Y}$ measurement was better than \pm 3 \% for all measurements. Due to the smaller quantity of $234 \mathrm{Th}$ in the uranium standard, the precision for this measurement was normally about $\pm 10 \%$. The results of the tracer studies are shown in Table IX.

TABLE IX

RESULTS OF THE TRACER STUDIES TO DETERMINE THE VIELD IN THE PRECIPITATION OF Th AND Y FLUORIDES

\begin{tabular}{|c|c|c|c|c|}
\hline $\begin{array}{r}\mathrm{ml} \text { of U } \\
234 \mathrm{Th} \text { Tracer } \\
\end{array}$ & $\begin{array}{c}\mu \mathrm{g} \\
\text { Nonradioactive } \\
\text { Th Spike } \\
\end{array}$ & $\frac{\mu \mathrm{g} T h}{\mathrm{~g} U}$ & $\begin{array}{c}\text { Recovery } \\
\text { 88 }\end{array}$ & $\begin{array}{l}8 \text { Recovery } \\
234 \mathrm{Th}\end{array}$ \\
\hline $\begin{array}{l}2 \\
2 \\
2 \\
0.5 \\
1.0 \\
2.0\end{array}$ & $\begin{array}{l}25 \\
100 \\
200 \\
100 \\
100 \\
100\end{array}$ & $\begin{array}{r}42 \\
120 \\
224 \\
431 \\
240 \\
120\end{array}$ & $\begin{array}{r}92.5 \\
88.1 \\
93.6 \\
93.4 \\
109.8 \\
92.3\end{array}$ & $\begin{array}{r}93.9 \\
98.5 \\
89.1 \\
106.0 \\
102.7 \\
93.4\end{array}$ \\
\hline
\end{tabular}

These results indicate that the percent of $\mathrm{Y}$ and $\mathrm{Th}$ precipitated is normally greater than $90 \%$ and essentially constant with varying amounts of $U$ and $T h$. The high yields also indicate that experimental conditions and analytical techniques are optimized for the best sensitivity. 


\section{PRECISION AND ACCURACY}

The precision and accuracy of the method was determined at two different levels of thorium in uranium. Six $4-m 1$ aliquots of the $481.41 \mathrm{~g} / 1$ iter uranium standard were analyzed without the addition of any other thorium and with 50 $\mathrm{ml}$ of $1.0 \mathrm{~N} \mathrm{HF}-1.0 \mathrm{~N} \mathrm{NH} 4 \mathrm{~F}$ mixture. Since the uranium standard contained $7.77 \mathrm{\mu g} \mathrm{Th} / \mathrm{ml}$ as determined by standard additions, these tests represent the precision and accuracy at the 16 $\mathrm{prh} / \mathrm{mpU}$ level. The second set of analyses were carried out by spiking $2 \mathrm{~m} 1$ of the $481.41 \mathrm{~g} / 1$ iter uranium standard with $100 \mathrm{\mu g}$ thorium and precipitating with a $30-\mathrm{ml}$ volume of the fluoride mixtures. These tests give the accuracy and precision of the method at the $120 \mathrm{pTh} / \mathrm{mpU}$ level. Table $\mathrm{X}$ contains the statistical results of these tests.

Data in Table $x$ indicate that low percent recoveries may be expected at thorium levels of $16 \mathrm{pTh} / \mathrm{mpU}$; however the data in Tables VI and IX indicate that quantitative results can be expected at the 70 and $42 \mathrm{pTh} / \mathrm{mpU}$ levels. Even though the accuracy of the method is not good at the lower levels, the precision is excellent. The low recoveries at the low level cannot be totally explained since tracer studies indicated that greater than 90\% recoveries were possible at the $42 \mathrm{pTh} / \mathrm{mpU}$ level. Therefore further tests are necessary between the 16 and $42 \mathrm{pTh} / \mathrm{mpU}$ levels in order to determine if the low recoveries were an experimental error or if the amount of Th has decreased to the point that the solubility of thorium fluoride is an important factor. Properly calibrated, the method should be capable of making accurate measurements near the $20 \mathrm{pTh} / \mathrm{mpU}$ level. 


\section{TABLE $X$}

PRECISION AND ACCURACY IN THE

DETERMINATION OF THORIUM IN URANIUM

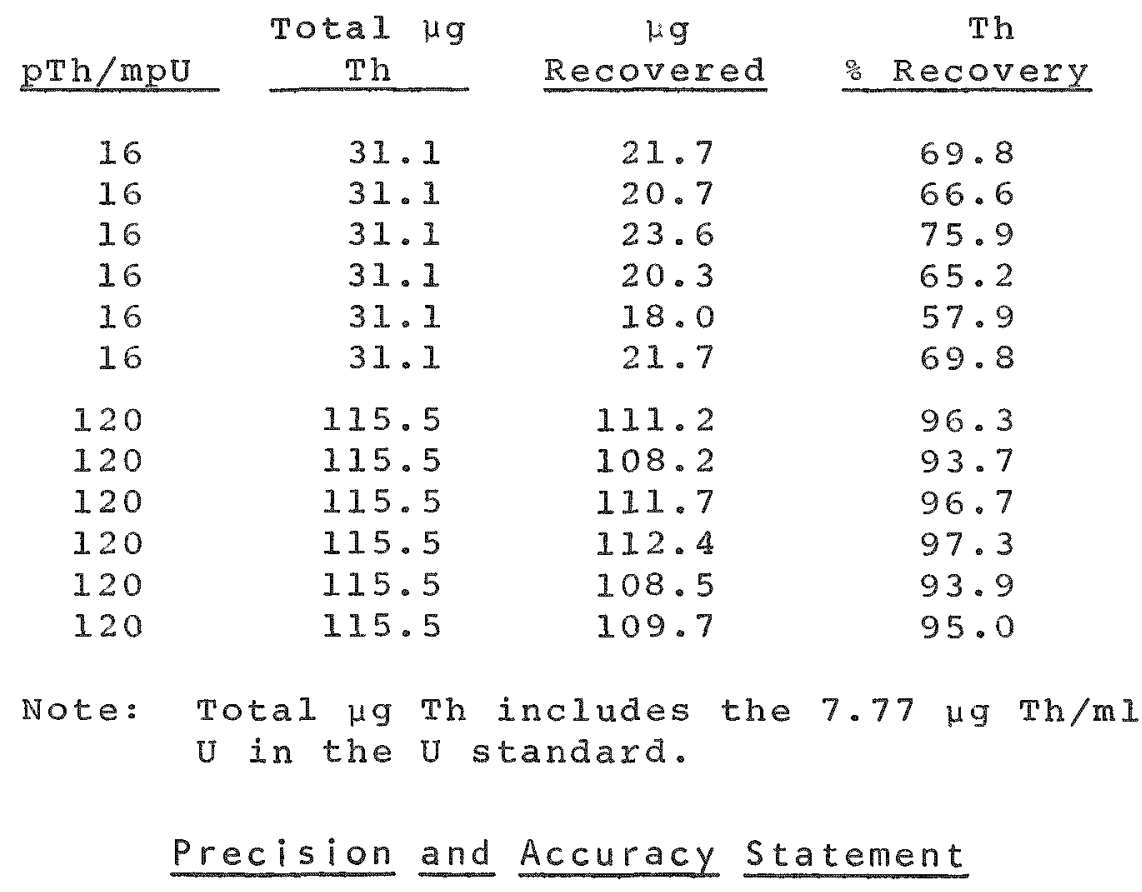

$$
\begin{aligned}
& 16 \mathrm{pTh} / \mathrm{mpU} \text { level } \bar{x}=21.0 \mu \mathrm{g} \pm 1.9 \mu \mathrm{g} \text { Total } \mu \mathrm{g} \text { Th } \\
& \bar{x}=69.5 \% \pm 6.0 \% \quad \% \text { Recovery } \\
& 120 \mathrm{pTh} / \mathrm{mpU} \text { level } \bar{x}=110.3 \mu \mathrm{g} \pm 1.7 \mu \mathrm{g} \text { Total } \mu \mathrm{g} \text { Th } \\
& \bar{x}=95.5 \pm 1.5 \% \quad \% \text { Recovery }
\end{aligned}
$$

\section{ACKNOWLEDGMENTS}

The author wishes to express appreciation to W. I. Louk for the laboratory work performed, to Eleanore Earhart for her secretarial assistance, to C. P. Mclaughlin and W. H. Zimmer for the gamma energy analyses, and to M. H. Campbell for editorial assistance. 


\section{REFERENCES}

1. C. J. Rodden, Analysis of Essential Nuclear Reactor Materials, Division of Technical Information, U. S. Atomic Energy Commission (1964).

2. D. I. Ryabchikov and E. K. Gol"braikh, "The Analytical Chemistry of Thorium," The MacMillan Company, New York (1963).

3. R. C. Sackville, "NP-7932," Eldorado Mining and Refining, Ltd. , Saskatchewan, Canada, Apri1 1956.

4. H. H. Willard, A. W. Mosen, and R. D. Gardner, "Volumetric Determination of Thorium in Uranium Alloys," Ana. Chem., Vol. 30, No. 10, pp. 1614-1616, October 1958.

5. C. L. Luke, "Determination of Traces of Fluorine and Sulfur by X-Ray Analysis,"Anal. Chim. Acta, 43, pp. $245-252$ (1968).

6. C. I. Luke, "Determination of Trace Elements in Inorganic and Organic Materials by X-Ray Fluorescence Spectroscopy " Anal. Chim. Acta, 41, pp. 237-250 (1968). 


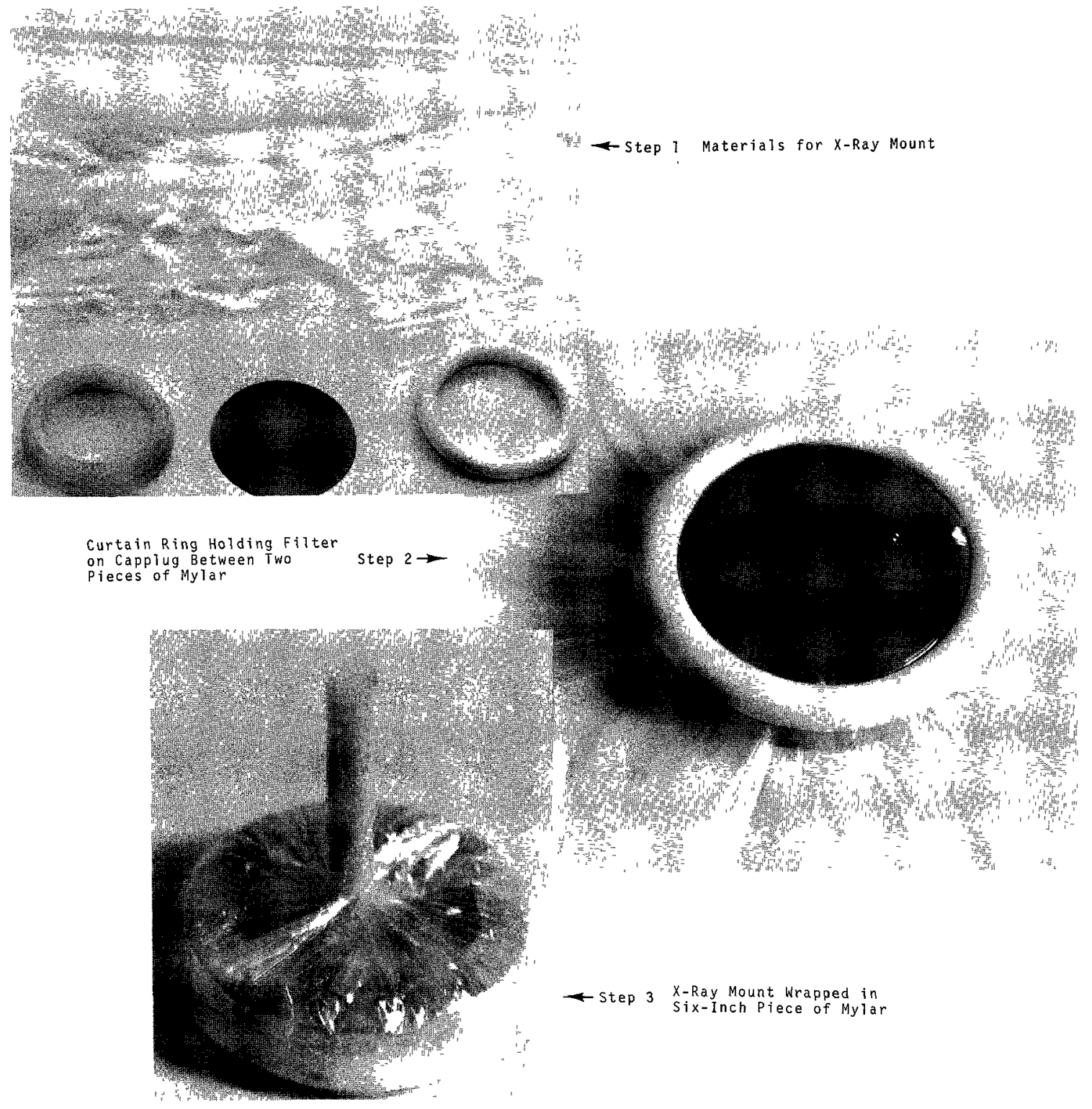

FIGURE 1

$X$-RAY MOUNTING PROCEDURE 


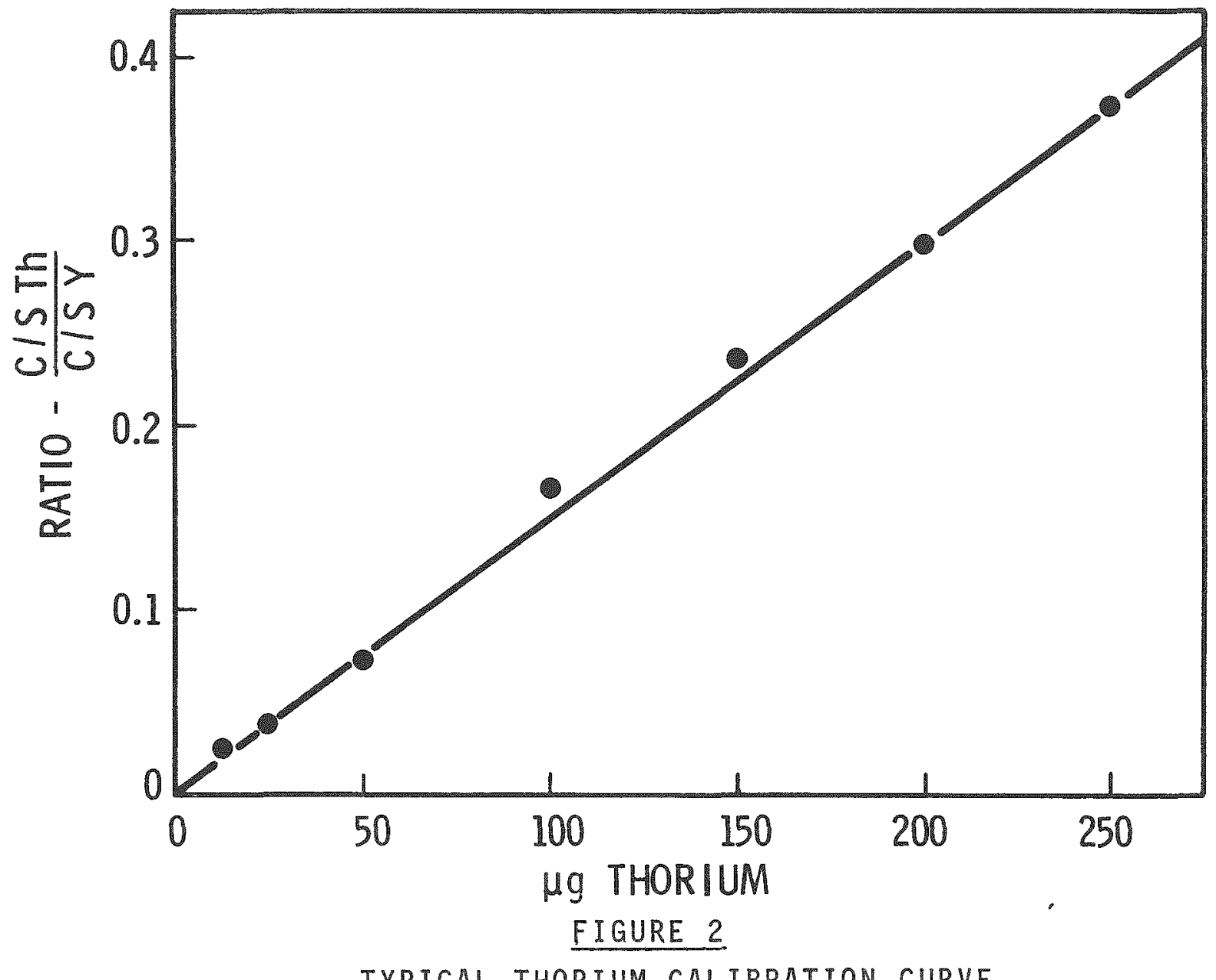




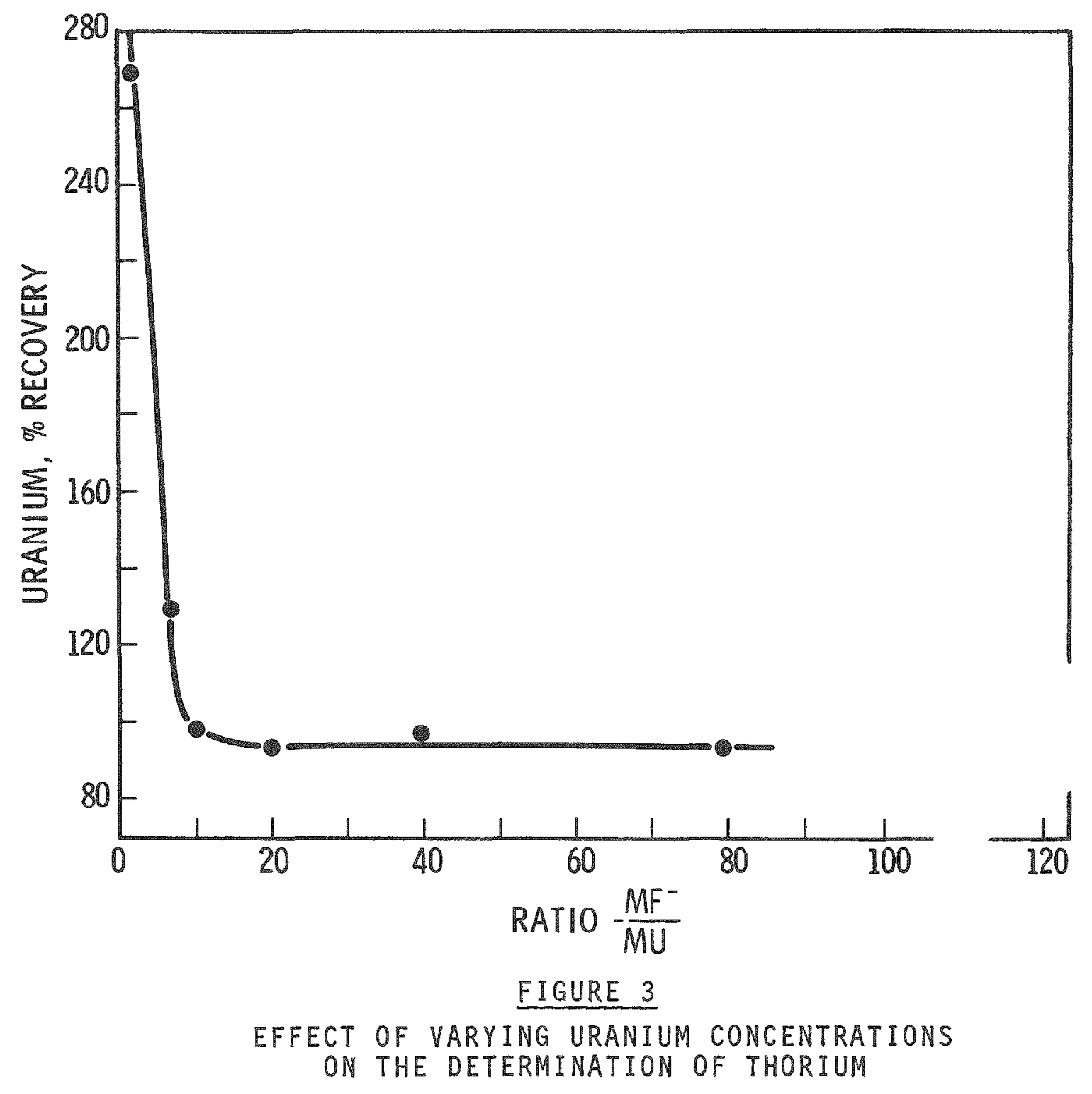




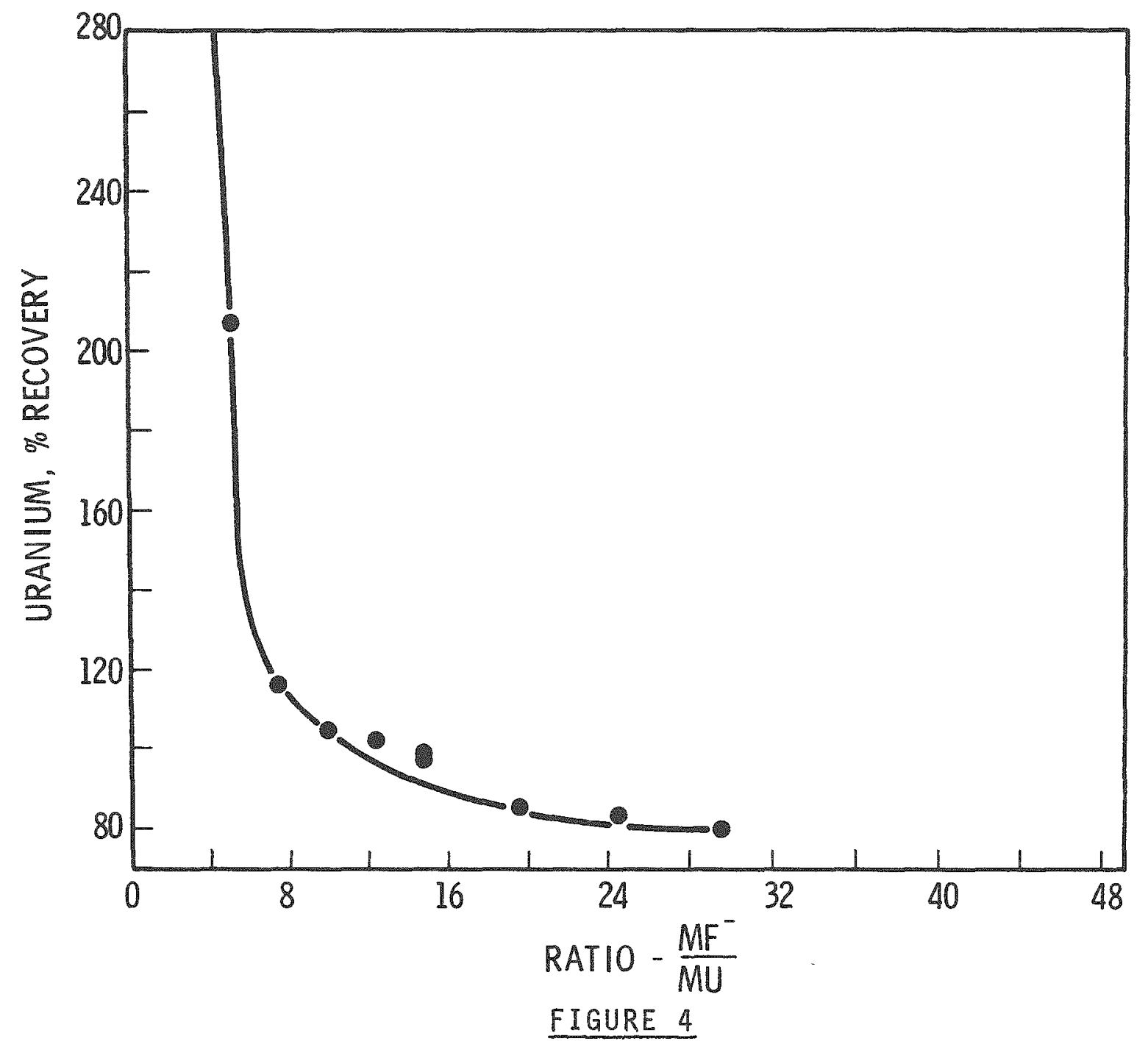

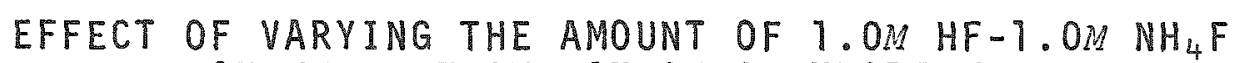
ON THE DETERMINATION OF THORIUM 
APPENDIX 


\section{APPENDIX}

\section{DETAILED PROCEDURE FOR THE DETERMINATION \\ OF THORIUM IN URANIUM NITRATE}

Note: Samples must conform to the limitations described in the procedure.

\section{SEPARATION PROCEDURE}

\section{Procedure}

1. Pour $30 \mathrm{mI}$ of the $1.0 \mathrm{M}$ $\mathrm{HF}-1.0 \mathrm{O} \mathrm{NH}_{4} \mathrm{~F}$ mixture into a 50-ml plastic beaker.

2. Pipet the uranium sample into the beaker and rinse the pipet once with $1 M \mathrm{HNO}_{3}$.

3. Pipet $200 \mu 1$ of the $1.00 \mathrm{~g} / \mathrm{liter}$ La carrier into the beaker.

4. Pipet exactly $200 \mu 1$ of 1.00 g/liter $Y$ internal standard into the beaker and rinse with two portions of $1 M \mathrm{HNO}_{3}$.

5. Add a Teflon stir bar and stir for $10 \mathrm{~min}$.

6. After stirring for 10 min, allow the solution comment

a. If more than $2.0 \mathrm{ml}$ of 500 g/liter uranium is used as a sample increase the

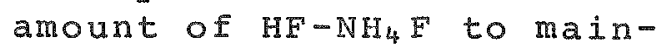
tain a $F^{-} / U$ ratio between $10 / 1$ and $15 / 1$.

b. Use gloves and proper precautions when handing $\mathrm{HF}$ $\mathrm{NH}_{4} \mathrm{~F}$.

c. Measure $\mathrm{HF}-\mathrm{NH}_{4} \mathrm{~F}$ in a graduate cylinder.

Do not rinse in $1.0 M \mathrm{HF}-1.0 \mathrm{O}$ $\mathrm{NH}_{4} \mathrm{~F}_{\text {matrix. }}$.

No rinse is necessary.

Pipeting must be accurate.

Use only Teflon stir bars.

While the solution is standing, prepare a Millipore filter 
Procedure

to stand for $30 \mathrm{~min}$.

7. Filter the sample solution by pouring $\simeq 5-\mathrm{mI}$ aliquots down the side of the filtering chimney with the aid of a rubber policeman.
8. After all the solution has been filtered, rinse the beaker with two 2.5-ml portions of $\mathrm{HF}-\mathrm{NH}_{4} \mathrm{~F}$. Police the beaker thoroughly and filter the solution as described in step 7 .

9. Rinse the chimney with approximately $5 \mathrm{mI}$ of ethanol.

10. Remove the filter and air-ary for 30 minutes.
Comment

apparatus by centering a

solvinert filter on the glass

frit and clamping on the

chimney. Wet the filter by applying vacuum and adding 2 or $3 \mathrm{ml}$ of the 1.OM HF-1.OM $\mathrm{NH}_{4} \mathrm{~F}$ solution.

a. Do not splash the solution or pour it directly onto the filter paper. Pouring directly on the filter paper may dislodge previously filtered precipitate causing it to collect on the sides of the glass chimney.

b. Do not fill the chimney too high with solution since the gelatinous precipitate may stick to the walls and become difficult to remove. Try to control the solution level to the lower 1 1/2" of the chimney.

A policeman is used to scrub any potential precipitate from the walls of the beaker into the rinse solution. The policeman should be used even though no precipitate is visible.

The alcohol wets the glass surface of the chimney better than the $\mathrm{HF}-\mathrm{NH}_{4} \mathrm{~F}$ solution and carries any precipitate on the chimney onto the filter. Excessive amounts of alcohol should not be used since the solubility of the precipitate in ethanol is not established.

Be careful in handing the filter to prevent disturbing the 
Procedure

11. While filters are drying, thoroughly wash the filter apparatus with deionized $\mathrm{H}_{2} \mathrm{O}$.

\section{Comment}

precipitate.

The $\mathrm{HF}-\mathrm{NH}_{4} \mathrm{~F}$ mixture will eventually destroy the glass frit in the Millipore filter unit. Washing the apparatus immediately will prolong the life of the frit.

\section{MOUNTING PROCEDURE (FIGURE I)}

1. Cut the SEP-14 Capplug so that it is about $6 \mathrm{~mm}$ tall with the bottom removed. Removing the bottom of the Capplug reduces the background caused by X-ray scattering from the plastic. Trim the inside of a curtain ring so that it will fit easily over the Capplug.

2. Place a $2^{\prime \prime} \times 2^{\prime \prime}$ square of Mylar on top of the Capplug.

3. Carefully place the filter on top of the Mylar (precipitate up) and center over the capplug.

4. Place another $2^{\prime \prime} \times 2^{\prime \prime}$ piece of Mylar on top of the filter paper, being careful not to disturb the precipitate.

5. With the filter paper sandwiched between the two pieces of Mylar and centered over the Capplug, place the trimmed curtain ring over the Capplug to hold the filter in place. The curtain ring should not have to be forced over the capplug but should fit tight enough to hold the filter into position.

6. Place a 6" 8 6" piece of Mylar over the Capplug pulling the excess behind the capplug into a tail so that the face of the filter is covered with a smooth surface of Mylar. Twist the excess Mylar into a tight tail and tape to prevent it from unwrapping. Cut off excess Mylar leaving the tail about 1/2" long. Label the $x-r a y$ mount using a small piece of masking tape.

\section{X-RAY COUNTING PROCEDURE}

1. Center the blank mount containing a solvinert filter with 
no chemical treatment in the holder so that the precipitate is exposed to the maximum $x-r a y$ flux.

2. Set up the $x-r a y$ instrument as follows:

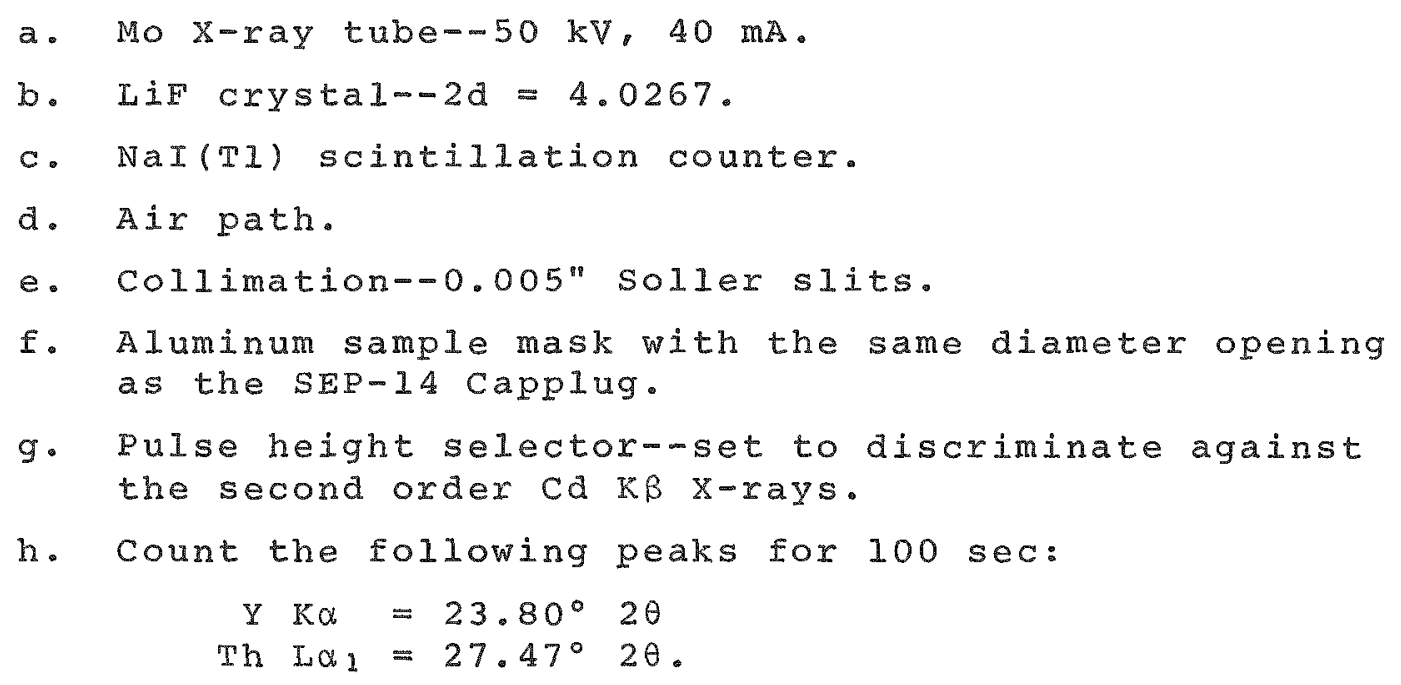

3. Count the blank at the designated peaks for 100 seconds and record the count rate.

4. Place a sample or standard into the sample holder and record the count rate for the sample or standard.

5. Continue to count all the samples or standards in this manner. When all the samples or standards have been counted, repeat the counts on the blank. The blank is counted before and after a series of standards or samples in order to correct the background for any instrumental shift. This may not be necessary if the instrument is highly stable; however it should improve the precision of the background measurement.

\section{CALIBRATION}

The instrument is calibrated by carrying between 12.5- and $250-\mu g$ aliquots of standard Th (no uranium) through the procedure as described. The ratio of the net count rate of the Th-to-Y is then determined according to I, II, and III of "Calculations." This ratio is then plotted versus the $\mu g$ Th and the linearity of the calibration examined. The plot should be linear over this region; however larger deviations will occur at the lower concentrations. A least squares fit 
to the points is then calculated where:

$$
\begin{aligned}
& y=R=\operatorname{ratio}=\frac{\operatorname{net} T h C / S}{\operatorname{net} Y C / S} \\
& \mathrm{x}=\mu \mathrm{g} \mathrm{Th} \\
& \mathrm{m}=\text { slope }=\frac{\text { ratio }}{\mu \mathrm{g} \mathrm{Th}} \\
& \text { I = intercept and } \\
& \mathrm{y}=\mathrm{mx}+\mathrm{b} \text { or } \\
& x=(y-b) \frac{1}{m} \\
& \mu g T h=\frac{(R-I)}{m}
\end{aligned}
$$

\section{CALCULATIONS}

I. Calculate the background count rate for the blank as follows:

$$
\begin{aligned}
& \text { Average } Y=\frac{C / S Y b l a n k \text { (before) }+C / S Y b l a n k \text { (after) }}{2} \\
& \text { Background } \\
& \begin{array}{l}
\text { Average Th } \\
\text { Background }
\end{array}=\frac{C / S \text { Thblank (before) }+C / S \text { Thblank (after) }}{2}
\end{aligned}
$$

I. Calculate the net count rate for samples or standards as follows:

Net $C / S Y=$ total $\mathrm{Y} / \mathrm{S} \mathrm{Y}_{\text {Sample }}-\mathrm{C} / \mathrm{S} \mathrm{Y}_{\text {average blank }}$ Net $\mathrm{C} / \mathrm{S} \mathrm{Th}=$ total C/S Thsample - C/S Thaverage blank

III. Calculate the ratio of the thorium to yttrium count rate as follows:

$$
R_{\frac{T h}{Y}}=\frac{\text { net } C / S T h}{\operatorname{net} C / S Y}
$$

IV. Calculate the $\mu \mathrm{g}$ Th in the sample by entering $R_{T h}$

$$
\mu g T h=\left(\frac{\mathbb{R}_{T h}}{\mathrm{Y}}-I\right) \frac{1}{\mathrm{~m}}
$$




$$
\text { where } \begin{aligned}
I & =\text { intercept } \\
\mathrm{m} & =\text { slope }=\frac{R_{\mathrm{Th}}}{\mu \mathrm{Y}}
\end{aligned}
$$

Determine the parts of thorium in a million parts of uranium $\mathrm{pTh} / \mathrm{mpu}$ as follows:

$$
\frac{p T h}{m p U}=\frac{\mu g T h(i n \operatorname{sample})}{g r a m s \text { in sample }}
$$

$g$ of $\mathrm{U}$ in sample $=$ (concentration $\mathrm{U}$ in $\mathrm{g} /$ liter $)($ sample size, $\mathrm{ml})\left(10^{-3} 1 \mathrm{iters} / \mathrm{ml}\right)$ 


\section{DISTRIBUT I ON}

\section{Number of Copies}

6

170

58
Atomic Energy Commission: Richland Operations office

O. J. Elgert (5)

H. D. Smith

Atomic Energy Commission Technical Information Center, Oak Ridge, TN

Atlantic Richfield Hanford Company

D. L. Anderson

K. R. Byers

M. H. Campbe11

A. H. Case

C. A. Colvin

N. R. Diebel

R. E. Felt

R. D. FOX

N. I. Harms

J. M. Harn 1ey

H. H. Hopkins, Jr.

R. E. Isaacson

J. W. Jordan

M. J. Kupfer

W. D. Luening

C. W. Malody

L. P. McRae

S. G. Metcalf

A. G. Miller

G. A. Nicholson

G. C. Oberg

D. J. Rochon

D. E. Sandberg

W. H. Sant

W. W. Schulz

H. P. Shaw

S. J. Shinker

A. E. Smith

H. E. Smith

G. T. Stocking

C. P. Sutter

M. J. Szulinski 


\section{DISTRIBUTION (continued)}

No. of Copies

Atlantic Richfield Hanford Company (continued)
D. E. Turner
D. I. Uebelacker
D. J. Washenfelder
R. E. Wheeler
W. I. Winters (15)
D. D. Wodrich

ARHCO Document Services (2) 